\title{
Acute Myocardial Infarction in Young Men Under 50 Years of Age: Clinical Characteristics, Treatment, and Long-Term Prognosis
}

\author{
Hui Gao' \\ Yuan Wang' \\ Aidong Shen' \\ Hui Chen (D) \\ Hongwei $\mathrm{Li}^{1-3}$ \\ 'Department of Cardiology, \\ Cardiovascular Center, Beijing Friendship \\ Hospital, Capital Medical University, \\ Beijing, 100050, People's Republic of \\ China; ${ }^{2}$ Department of Internal Medical, \\ Medical Health Center, Beijing Friendship \\ Hospital, Capital Medical University, \\ Beijing, 100050, People's Republic of \\ China; ${ }^{3}$ Beijing Key Laboratory of \\ Metabolic Disorder Related \\ Cardiovascular Disease, Beijing, 100069 , \\ People's Republic of China
}

\begin{abstract}
Aim: The prevalence of acute myocardial infarction (AMI) is increasing in young adults, especially in men. This study aims to compare the characteristics and explore the association between age and clinical outcomes in male adults who first experienced AMI.

Methods: A total of 2737 male patients with AMI were divided into three groups by age: $<50,50-65$, and $\geq 65$ years. Clinical characteristics and long-term results (all-cause and cardiac deaths, nonfatal MI, revascularization, nonfatal stroke, cardiac rehospitalization) were identified across different age subgroups. The association between age and the outcomes was assessed by Cox proportional hazard models.

Results: This population was followed up for a median of 36.7 months. Patients $<50$ years had a lower prevalence of diabetes $(19.4 \%)$ and previous stroke $(1.8 \%)$, while they were more often to be smokers $(77.1 \%)$, obese $(26 \%)$, dyslipidemia $(74.7 \%)$, and with the singlevessel disease $(16.2 \%)$. The risk of cardiovascular and all-cause death in patients $\geq 65$ years was higher than patients $<50$ years, which was noticed through competing risk regression analysis after adjusting for confounding factors (adjusted HR 3.24; 95\% CI 2.26-4.22, $p=0.020$ for cardiovascular death, adjusted HR 4.17; 95\% CI 1.91-9.10, $p<0.001$ for allcause death).
\end{abstract}

Conclusion: In conclusion, although men who suffered from first AMI under the age of 50 had lower mortality, they had a higher burden of modifiable traditional risk factors. The management of modifiable lifestyles should be addressed to all young AMI patients.

Keywords: acute myocardial infarction, young men, the long-term prognosis

\section{Introduction}

Acute myocardial infarction (AMI) remains a primary reason for morbidity and mortality globally. AMI in young populations which can lead to death in their life, resulting in a major public health crisis is not intensively investigated. ${ }^{1}$ Although the prevalence of AMI has decreased in older patients, younger individuals who experience AMI have not had the same declines in cardiovascular events, especially men. $^{2}$ The clinical characters of AMI vary by age. Previous studies have identified that risk factors included tobacco use, obesity, and diabetes may be crucial to young individuals. $^{3-5}$ The Framingham Heart Study had shown that the young men aged under 45 years remain adverse outcomes after present with AMI over a decade follow-up period. ${ }^{6}$ Compared to the elderly, the young are not well studied about the prevalence, comorbidities, and therapies. Moreover, current studies have focused on the age of 40 or 45 years while there has not been a clear definition 
of young in patients with AMI. $^{7}$ In particular, relevant researches about Chinese men who received the percutaneous coronary intervention (PCI) are limited. Therefore, in our study, we assessed the major baseline features, angiography characteristics, treatments, and long-term follow-up in young AMI men under the age of 50 years.

\section{Methods}

\section{Subjects}

The data source was from the Cardiovascular Center of Beijing Friendship Hospital Database (CBD) Bank. A cohort of 5170 Chinese adults who were diagnosed with AMI (according to the Fourth Universal Definition of Myocardial Infarction) from January 2013 to August 2020 was included in our study. Of them, 2433 were excluded based on the following exclusion criteria: (1) female, (2) with a previous episode of AMI, (3) without coronary angiography, (4) with missing data on baseline characteristics or long-term results. Finally, we identified 2737 male patients who performed with coronary angiography in this retrospective study. Enrolled individuals were categorized into three groups based on their age: $<50$ years (young), 50-64 years, and $\geq 65$ years. Individuals were followed up at 1, 3, 6 months, and each year after discharge. The median follow-up time is 36.7 (IQR: 36.3, 37.2) months.

\section{Data Collections and Definitions}

The progress of the data collected was consistent with the Declaration of Helsinki. The collection was permitted by the Institutional Review Board of Beijing Friendship Hospital affiliated to Capital Medical University.

We collected information including basic demographic data, medical histories, laboratory values, echocardiography findings, angiographic evaluations, medications at discharge and length of hospital stay from relevant medical records. Additionally, information on the type of AMI was also available for each participant. Outcome data included cardiovascular (CV) death, all-cause mortality, recurrence of MI, non-fatal stroke, rehospitalization for heart failure, and revascularization. Furthermore, causes of noncardiovascular death were recorded in our analysis. We collected follow-up results over the telephone between trained clinicians and patients or their relatives. Outcomes were obtained via telephone follow-up.

The clinical definition of AMI was in accordance with the Fourth Universal Definition of MI during the study period. ${ }^{8}$ Hypertension was defined with a raised blood pressure higher than $140 / 90 \mathrm{mmHg}$ or treated with antihypertensive drugs. Diabetes mellitus was defined with an elevated fasting blood glucose $>126 \mathrm{mg} / \mathrm{dL}(7.0 \mathrm{mmol} / \mathrm{L})$ or random blood glucose $>200 \mathrm{mg} / \mathrm{dL}(11.1 \mathrm{mmol} / \mathrm{L})$ or previously diagnosed or treated with antidiabetic medication. Dyslipidemia was defined with an elevated lowdensity lipoprotein cholesterol (LDL-C) $\geq 130 \mathrm{mg} / \mathrm{dL}$ $(3.3 \mathrm{mmol} / \mathrm{L})$, total cholesterol $(\mathrm{TC}) \geq 200 \mathrm{mg} / \mathrm{dL}(5.2$ $\mathrm{mmol} / \mathrm{L})$, triglyceride $(\mathrm{TG}) \geq 150 \mathrm{mg} / \mathrm{dL}(1.7 \mathrm{mmol} / \mathrm{L})$ or previously diagnosed or treated with lipid-lowering drugs. The level of high-density lipoprotein cholesterol (HDL-C) lower than $40 \mathrm{mg} / \mathrm{dL}(1.0 \mathrm{mmol} / \mathrm{L})$ in men or $50 \mathrm{mg} / \mathrm{dL}(1.3 \mathrm{mmol} / \mathrm{L})$ in women was also defined as dyslipidemia. Body mass index (BMI) higher than $30 \mathrm{~kg} /$ $\mathrm{m}^{2}$ was defined as Obesity.

Transthoracic echocardiography was carried out in all individuals on admission to evaluate LVEF, left atrial (LA) diameter, left ventricular end-diastolic dimension (LVEDD), and left ventricular end-systolic dimension (LVESD). Each individual underwent coronary angiography via the radial or femoral approach, where PCI was performed after it if necessary. CV mortality was defined as heart-related death. All-cause mortality was described as death for any reason. Non-fatal stroke was described as a cerebral disorder and supported by brain CT scans or MRI detection. Cardiac rehospitalization was defined as being hospitalized due to heart failure. Revascularization was described as the unplanned restoration of blood flow for ischemic symptoms and events.

\section{Statistical Analysis}

The collected data were analyzed using the R Programming Language and SPSS version 25.0 (IBM Inc, Armonk, New York). Continuous variables were revealed as mean with standard deviation or median with interquartile range, and comparison between categories was analyzed using Student's T-tests or Wilcoxon ranksum test as appropriate. Categorical variables were presented as counts and percentages, and differences between groups were analyzed using the chi-square test. Gray's test was applied to compare the independent prediction of age on CV mortality, recurrence of MI, revascularization, nonfatal stroke, cardiac rehospitalization due to the competitive risk from all-cause deaths. The competing risk regression curves were calculated for the cumulative incidence of outcomes. Covariates like patterns of AMI, left main coronary artery (LM), hypertension, diabetes, 
dyslipidemia, previous stroke, CKD, smoking, aspirin treatment, the peak level of NT-proBNP, the peak level of TnI, pre-PCI TIMI 0/1 flow, BMI, LVEF $<50 \%$ were involved in the multivariate assessment. All $p$ values were two-tailed, and $p<0.05$ was considered statistically significant.

\section{Results}

\section{Study Population}

Baseline characteristics of all subjects in this research are presented in Table 1. In total, we recruited 2737 male patients. The mean age of the overall study population was 61 years. Of these people, $13.7 \%$ were aged younger than 50 years, $51.1 \%$ were aged 50 to 65 years, and $35.1 \%$ were aged 65 years or older. There were more patients $<50$ years present with STEMI than NSTEMI when compared with those aged $50-65$ years and those $\geq 65$ years.

\section{Risk Factors}

Patients $<50$ years presented less with diabetes mellitus and previous stroke compared with patients 50-65 years and $\geq 65$ years, as shown in Table 1 . Young men under 50 years old had fewer cardiovascular risk factors compared with the other two groups except for smoking (77.1\%) and obesity (26\%). Median peak troponin and CK-MB in young patients indicated that more heart muscle was affected in them. Although CK-MB and troponin levels were significantly higher in men younger than 50 years compared with those aged 50 to 65 years, the LVEF was similar between the two groups. Among men $<50$ years, BMI over $30 \mathrm{~kg} / \mathrm{m}^{2}$ was $26 \%$, and LDL-C levels over $120 \mathrm{mg} / \mathrm{dl}(3.0 \mathrm{mmol} / \mathrm{L})$ was 39\% (Figures 1 and 2 ).

\section{Angiographic Characteristics}

Coronary angiographic procedures were carried out in all subjects and the findings can be found in Table 1. Singlevessel occlusion and TIMI 0/1 coronary blood flow before the percutaneous coronary intervention were more common in patients $<50$ years (all $p<0.001$ ). The number of stenosed coronary arteries increased with aging (all $p<$ 0.001). Besides, the most frequently affected coronary segment according to our study was the left anterior descending coronary artery (LAD) among the 3 groups. Those individuals under the age of 50 were less likely to be LM, LAD, left circumflex artery, and right coronary artery disease when compared with patients $\geq 65$ years (all $p<$ 0.001). Patients with IABP, ventilator and CABG were significantly higher in men older than 65 years compared with those aged younger than 50 years $(p<0.05)$.

\section{Medications at Discharge}

The median period of hospitalization was 7 days $(25$ th, 75 th percentile: 6,9$)$ in patients $<50$ years and 50-65 years, 8 days (25th, 75th percentile: 6,11 ) in patients $\geq 65$ years old $(p<0.001)$. Patients $<50$ years were significantly less likely to be discharged on calcium channel blockers (CCB, $p=$ $0.002)$, and diuretics $(p<0.001)$ when compared with patients $\geq 65$ years, as shown in Table 1 . However, young patients received more prescriptions of beta-blockers. No differences were observed in the number of patients receiving aspirin, non-aspirin antiplatelet, ACEI or ARB, statin, and ezetimibe by age group (all $p>0.05$ ).

\section{Outcomes}

Over a median follow-up period of 36.7 months (interquartile range: $36.3-37.2$ months), there were 194 (7.1\%) deaths in our cohort, representing $1.9 \%$ of patients $<50$ years and $13.9 \%$ of patients $\geq 65$ years $(p<0.001)$. Mortality rates between patients $\geq 65$ years $(n=134$; $13.9 \%), 50-65$ years $(\mathrm{n}=53 ; 3.8 \%)$ and $<50$ years $(\mathrm{n}=$ $7 ; 1.9 \%$ ) differed significantly. Young patients showed a more favorable outcome compared with the other two age groups. One hundred and four were dead due to cardiovascular-related causes, 53 as non-CV deaths, and 37 were undetermined. Men $<50$ years had a higher percentage of respiratory failure and other causes of death than the elderly (Tables 2 and 3 ).

Figure 3 and Table 3 reveal the analysis of outcomes based on competition from all-cause death. The cumulative occurrence of $\mathrm{CV}$ mortality, revascularization, nonfatal stroke increased significantly with elevated age groups except for recurrence of MI and rehospitalization for heart failure. After adjusting for patterns of acute myocardial infarction, hypertension, diabetes, dyslipidemia, and other confounding factors, patients $\geq 65$ years still had a higher $\mathrm{CV}$ and all-cause mortality than patients $<50$ years. On adjusted competing risk modeling, the hazard ratio $(\mathrm{HR})$ of $\mathrm{CV}$ death $(\mathrm{HR}=3.24,95 \% \mathrm{CI}$ 2.26-4.22, Gray's test $p=0.02$ ) and all-cause death (HR $=4.17,95 \%$ CI $1.91-9.10$, Gray's test $p<0.001)$ remaining significant.

\section{Discussion}

This retrospective analysis focused on the between-group comparisons of characteristics, treatment, and outcomes of 


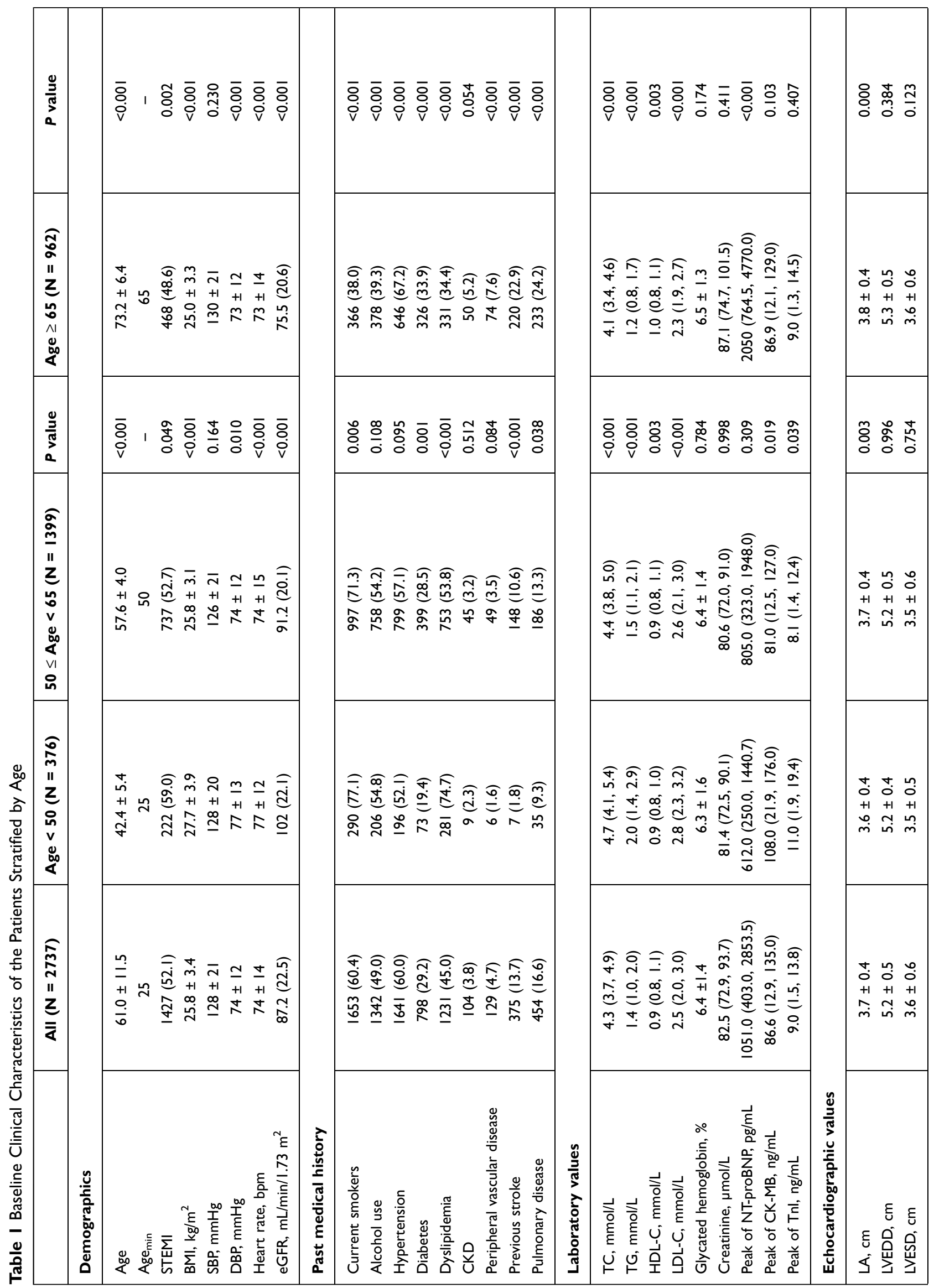




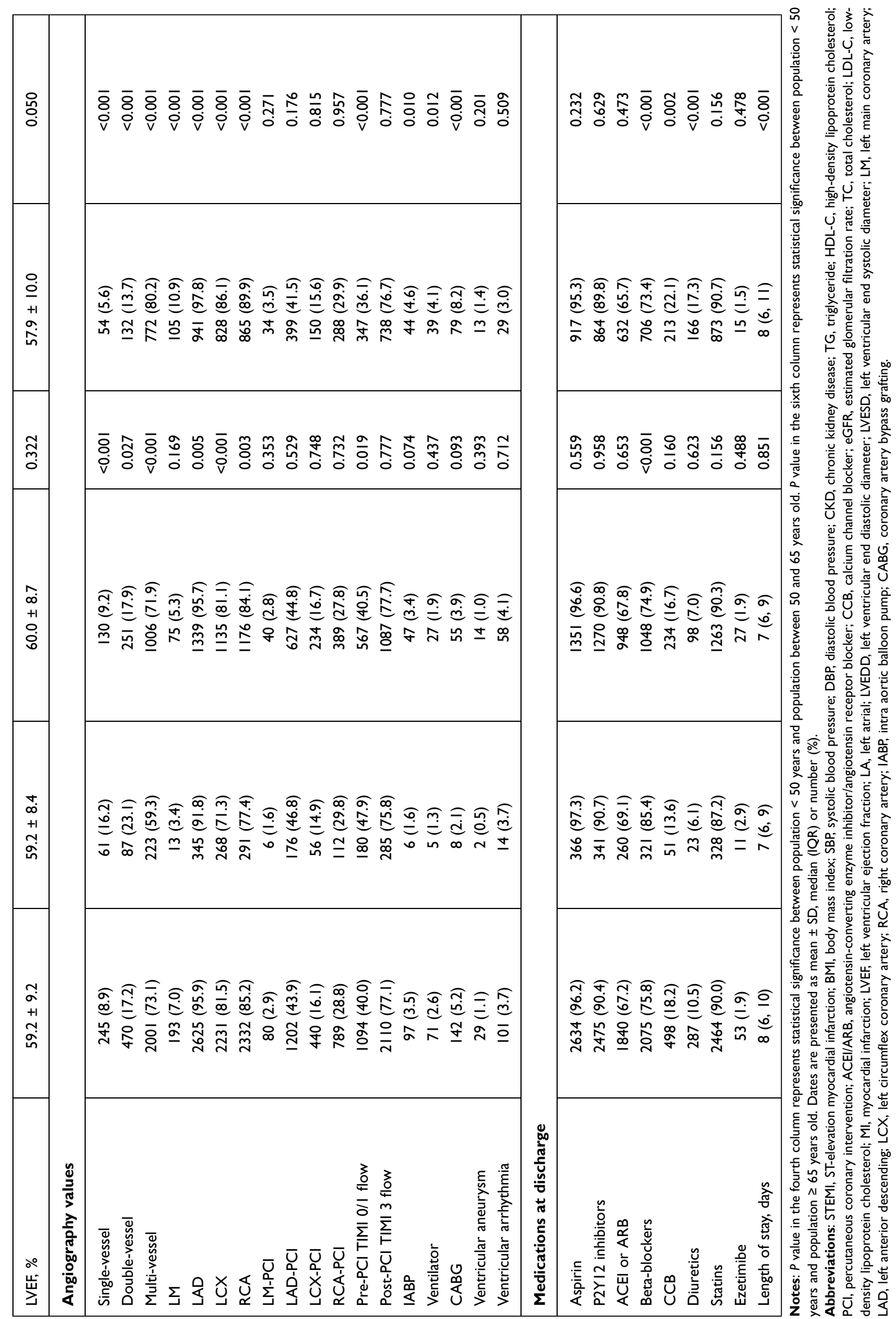




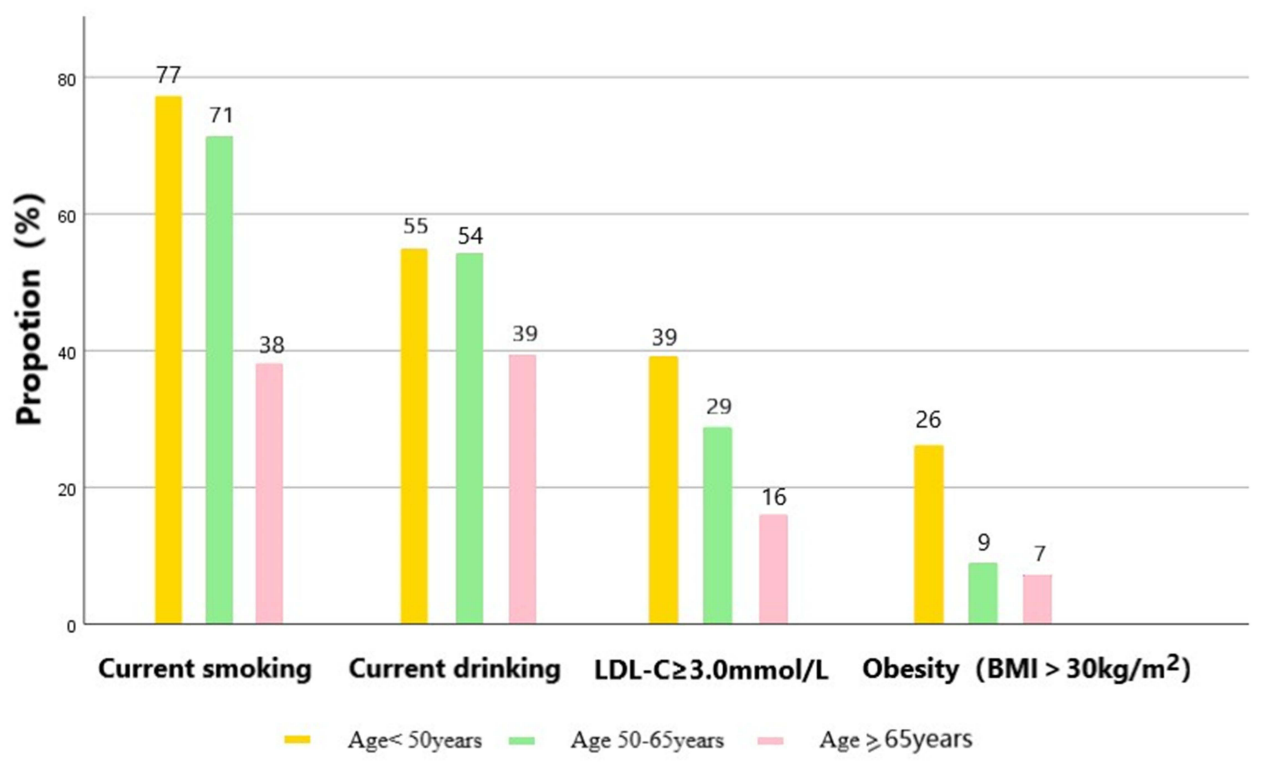

Figure I Modifiable risk factors in patients with myocardial infarction.

Abbreviations: LDL-C, low-density lipoprotein cholesterol; BMI, body mass index.

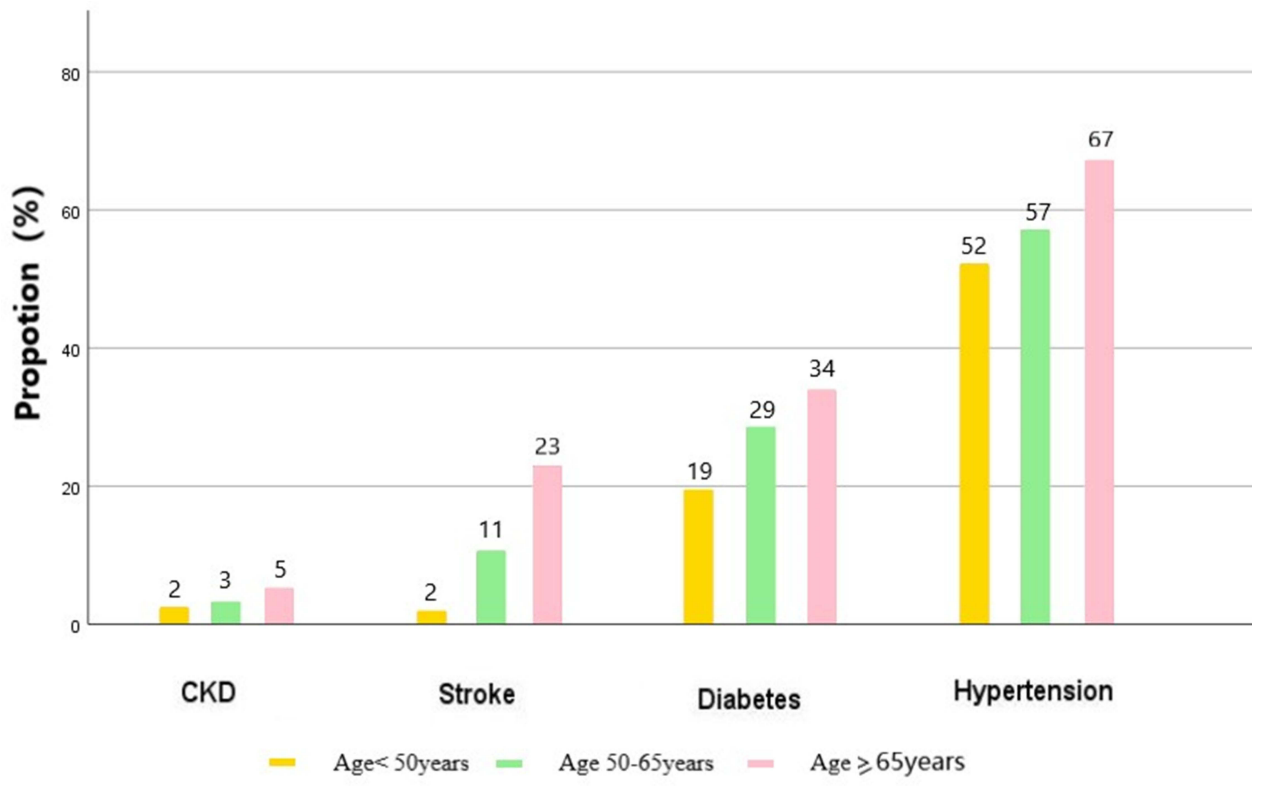

Figure 2 Unmodifiable risk factors in patients with myocardial infarction.

Abbreviation: CKD, chronic kidney disease.

AMI according to age. About 52.1\% presented with STEMI. The proportion of patients $<50$ years representing $13.7 \%$ of all AMI patients in our study. We observed an obvious increase in younger men presenting with modifiable cardiovascular risk factors, including smoking, drinking, and obesity which account for nearly one out of four patients. Compared with older men, younger men were less probably to be present with diabetes, previous stroke, or hypertension. Besides, men aged $\geq 50$ years had more multi-vessel diseases. Young adults under the age of 50 had a significantly lower CV and all-cause mortality in comparison to the over 65 years group. The significant differences still exist after adjusting baseline confounders.

Although AMI in young patients is rare, the incidence of AMI in this population is increasing. A 10-year followup data indicated that the prevalence of AMI was higher in 
Table 2 Causes of Death Among Patients Who Experienced Non-Cardiovascular Death

\begin{tabular}{|l|c|c|c|c|}
\hline Cause of Death & All (N = 90) & Age < 50 (N = 2) & $\mathbf{5 0} \leq$ Age < 65 (N = 27) & Age $\geq \mathbf{6 5}(\mathbf{N}=\mathbf{6 I})$ \\
\hline Cancer & $22(24.4)$ & $0(0.0)$ & $7(25.9)$ & $15(24.6)$ \\
Sepsis & $4(4.4)$ & $0(0.0)$ & $0(0.0)$ & $4(6.6)$ \\
Respiratory failure & $8(8.9)$ & $\mathrm{I}(50.0)$ & $\mathrm{I}(3.7)$ & $6(9.8)$ \\
Renal failure & $7(7.8)$ & $0(0.0)$ & $2(7.4)$ & $5(8.2)$ \\
Gastrointestinal bleed & $3(3.3)$ & $0(0.0)$ & $0(0.0)$ & $3(4.9)$ \\
Cerebrovascular disease & $9(10.0)$ & $0(0.0)$ & $8(29.6)$ & $\mathrm{I}(1.6)$ \\
Other & $37(41.1)$ & $\mathrm{I}(50.0)$ & $9(33.3)$ & $27(44.3)$ \\
\hline
\end{tabular}

Table 3 Competing Risk Model of Outcomes

\begin{tabular}{|c|c|c|c|c|c|}
\hline & Events (\%) & Unadjusted HR (95\% Cl) & $p$ value & Adjusted HR (95\% Cl) & $p$ value \\
\hline \multicolumn{6}{|l|}{ CV death } \\
\hline Age $<50$ & $5(1.3)$ & Ref & $-/-$ & Ref & $-/-$ \\
\hline Age $50-65$ & $26(1.9)$ & $1.39(0.54,3.60)$ & 0.500 & $0.99(0.37,2.60)$ & 0.980 \\
\hline Age $\geq 65$ & $73(7.6)$ & $5.96(2.42,14.7)$ & $<0.001$ & $3.06(1.12,8.35)$ & 0.029 \\
\hline \multicolumn{6}{|c|}{ Cardiac rehospitalization } \\
\hline Age $<50$ & $7(1.9)$ & Ref & $-/-$ & Ref & $-/-$ \\
\hline Age $50-65$ & $33(2.4)$ & I.12(0.49, 2.55) & 0.790 & $1.21(0.53,2.76)$ & 0.650 \\
\hline Age $\geq 65$ & $34(3.5)$ & $1.35(0.58,3.13)$ & 0.490 & I.19(0.46, 3.08) & 0.710 \\
\hline \multicolumn{6}{|c|}{ Non-fatal MI } \\
\hline$A g e<50$ & $15(4.0)$ & Ref & $-/-$ & Ref & $-/-$ \\
\hline Age $50-65$ & $4 I(2.9)$ & $0.67(0.37,1.21)$ & 0.190 & $0.65(0.34,1.20)$ & 0.170 \\
\hline Age $\geq 65$ & $36(3.7)$ & $0.73(0.39,1.36)$ & 0.310 & $0.83(0.39,1.69)$ & 0.610 \\
\hline \multicolumn{6}{|c|}{ Revascularization } \\
\hline$A g e<50$ & $24(6.4)$ & Ref & $-/-$ & Ref & $-/-$ \\
\hline Age $50-65$ & $99(7.1)$ & $1.06(0.68,1.66)$ & 0.790 & $1.06(0.66,1.70)$ & 0.820 \\
\hline Age $\geq 65$ & $42(4.4)$ & $0.62(0.38,1.04)$ & 0.069 & $0.75(0.4 I, I .37)$ & 0.350 \\
\hline \multicolumn{6}{|c|}{ Non-fatal stroke } \\
\hline Age $<50$ & $\mathrm{I}(0.3)$ & Ref & $-/-$ & Ref & $-/-$ \\
\hline Age 50-65 & $28(2.0)$ & $7.25(0.99,53.20)$ & 0.052 & $6.2 \mathrm{I}(0.85,45.3 \mathrm{I})$ & 0.070 \\
\hline Age $\geq 65$ & $28(2.9)$ & $10.20(1.39,75.00)$ & 0.023 & $6.86(0.85,55.09)$ & 0.070 \\
\hline \multicolumn{6}{|c|}{ All cause death } \\
\hline Age $<50$ & $7(1.9)$ & Ref & $-/-$ & Ref & $-/-$ \\
\hline Age $50-65$ & $53(3.8)$ & $2.02(0.92,4.44)$ & 0.079 & $1.40(0.63,3.11)$ & 0.380 \\
\hline Age $\geq 65$ & $134(13.9)$ & $8.21(3.85, \mid 7.5 I)$ & $<0.001$ & $4.16(1.83,9.47)$ & $<0.001$ \\
\hline
\end{tabular}

Notes: Adjusted factors included patterns of acute myocardial infarction, LM, hypertension, diabetes, dyslipidemia, previous stroke, CKD, smoking, Beta-blockers treatment, peak of NT-proBNP, peak of Tnl, pre-PCI TIMI 0/I flow, BMI, LVEF $<50 \%$.

Abbreviations: CV, cardiovascular; MI, myocardial infarction; LM, left main coronary artery; CKD, chronic kidney disease; BMI, body mass index; LVEF, left ventricular ejection fraction.

men than women between 30 and 55 years. ${ }^{9}$ Nearly three in four young adults can experience symptoms of cardiac ischemia, which was higher in men than in women. ${ }^{7}$
Similar results can be found in several studies. ${ }^{10-14}$ Development of AMI at a young age is correlated with multiple cardiovascular risk factors files, such as smoking, 

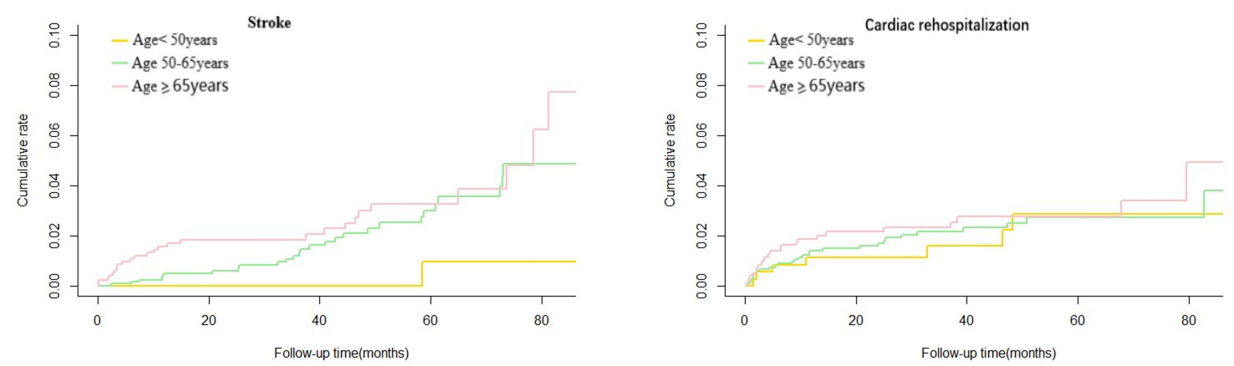

Number at risk

Number at risk

Age < 50years

$\begin{array}{ccccc}376 & 271 & 155 & 95 & 30 \\ \begin{array}{c}\text { Age } 50-65 \text { years } \\ 1399\end{array} & 987 & 585 & 369 & 88 \\ \begin{array}{c}\text { Age } \geq 65 \text { years } \\ 962\end{array} & 629 & 371 & 207 & 43\end{array}$

Age < 50years

$\begin{array}{ccccc}\begin{array}{c}\text { Age }<\text { 50years } \\ 376\end{array} & 269 & 155 & 94 & 30 \\ \begin{array}{c}\text { Age } 50-65 \text { years } \\ 1399\end{array} & 973 & 582 & 374 & 90 \\ \begin{array}{c}\text { Age } \geq 65 \text { years } \\ 962\end{array} & 622 & 367 & 207 & 43\end{array}$
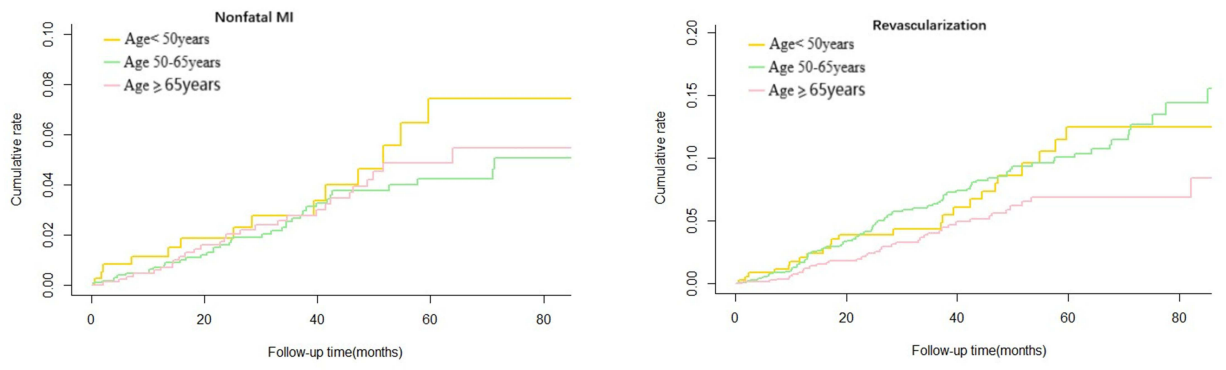

Number at risk

Age < 50years

$\begin{array}{ccccc}376 & 266 & 152 & 92 & 30 \\ \begin{array}{c}\text { Age } 50-65 \text { years } \\ 1399\end{array} & 981 & 576 & 368 & 88 \\ \begin{array}{c}\text { Age } \geq 65 \text { years } \\ 962\end{array} & 626 & 358 & 201 & 42\end{array}$

Number at risk

Age < 50years

\begin{tabular}{|c|c|c|c|c|}
\hline 376 & 261 & 146 & 84 & 27 \\
\hline \multicolumn{5}{|c|}{ Age $50-65$ years } \\
\hline 1399 & 960 & 553 & 348 & 81 \\
\hline \multicolumn{5}{|c|}{ Age $\geq 65$ years } \\
\hline 962 & 625 & 354 & 198 & 42 \\
\hline
\end{tabular}
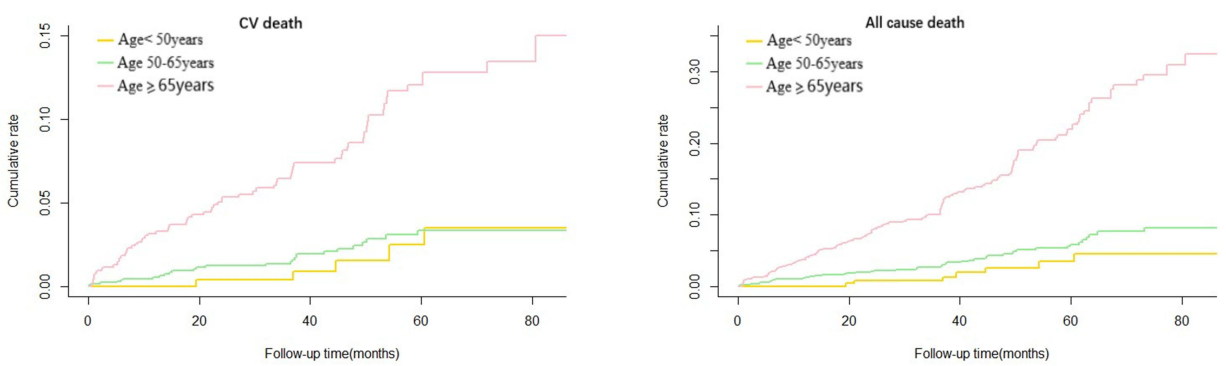

Number at risk

Age < 50years

$\begin{array}{ccccc}\begin{array}{c}376 \\ \text { Age } 50-65 \text { years } \\ 1399\end{array} & 271 & 155 & 96 & 30 \\ \begin{array}{c}\text { Age } 265 \text { years } \\ 962\end{array} & 992 & 596 & 381 & 93 \\ 962 & 375 & 211 & 45\end{array}$

Number at risk

Age < 50years

$\begin{array}{ccccc}376 & 271 & 155 & 96 & 30 \\ \begin{array}{c}\text { Age } 50-65 \text { years } \\ 1399\end{array} & 992 & 596 & 381 & 93 \\ \begin{array}{c}\text { Age } \geq 65 \text { years } \\ 962\end{array} & 638 & 375 & 211 & 45\end{array}$

Figure 3 Competing risk regression curves for $\mathrm{CV}$ death, non-fatal MI, non-fatal stroke, cardiac rehospitalization, and revascularization for the Age $<50$ years group (yellow line), Age 50-65 years group (green line) and Age $\geq 65$ years group (pink line).

Abbreviations: CV, cardiovascular; MI, myocardial infarction. 
hypertension, dyslipidemia, overweight, and inactivity. ${ }^{15}$ One of the most frequent causes of MI in younger individuals is plaque instability which was comparable to the old. ${ }^{16}$ Modifiable risk factors include smoking, obesity, and hyperlipidemia which were most commonly observed among young subjects in our study. Bentzon et al found that the high rate of plaque rupture coexists with the population of metabolic disorders. ${ }^{17}$ Smoking and hyperlipidemia are two important risk factors accounting for almost two-thirds of patients with AMI. ${ }^{7}$ The number of smoking was over three quarters in young patients. Frequent exposure to cigarette smoking can result in endothelial dysfunction due to the damage of arterial cells, especially start at an early age. ${ }^{18}$ Hyperlipidemia appears to be one of the most common risk factors. Several unconventional risk factors such as lipoprotein (a), inflammation, and genetic variations were also found, which may also explain some of the reasons for the early occurrence of MI. ${ }^{19,20}$ Our data showed that almost $40 \%$ of patients $<50$ years with a high level of LDL-C over $120 \mathrm{mg} / \mathrm{dl}$. Besides, nearly half of these young adults with coronary heart disease are obese. ${ }^{21}$ The incidence of obesity in our study is $26 \%, 9 \%, 7 \%$ in the three age groups, respectively. The development of MI at an early age is associated with obesity which accelerated atherosclerotic progression. Increasing the prediction of BMI $\geq$ $25 \mathrm{~kg} / \mathrm{m}^{2}$ on MI in younger subjects can be observed by Chen et al. ${ }^{22}$ These similar observations can be found in previously reported studies. ${ }^{23-26}$

PCI is considered the golden criterion therapy for AMI. Angiography was performed in all patients in our study through a femoral or radial artery approach by at least two interventional cardiologists. A study including 2528 patients indicated that single vessel occlusion was observed more prevalent in patients under the age of 40 years. ${ }^{5}$ Additionally, they had a lower extent of plaque and overall plaque burden than patients aged 41 to 50 . According to the American Heart Association, the LAD was the most frequently affected branch of all ages. In 2019, a cohort study of the Germans discovered that less than one-third of the older patients ( $>40$ years) had onevessel disease compared with the younger group ( $\leq 40$ years). ${ }^{26}$ We found a lower prevalence of multi-vessel, $\mathrm{LM}, \mathrm{LAD}, \mathrm{LCX}$, and RCA disease in men $<50$ years compared with the other two groups. In line with previous findings, the young were more frequently to have the single-vessel occlusion. ${ }^{27,28}$ There was an increasing tendency of diseased vessels with increasing age. ${ }^{29}$ One explanation is the multi-vessel disease occurred more commonly in individuals who have a history of diabetes. In our study, the old had a higher prevalence of diabetes. We also found that the young had more TIMI $0 / 1$ flow before PCI. The effect of coronary collateral circulation is a compensation way after the block of the normal coronary circulation.

Several previous studies have revealed a more positive prognosis in the young than the old with AMI. ${ }^{11,12,30,31}$ A study from Norway showed nearly one in ten individuals with AMI under 45 years died or underwent non-obstructive coronary artery disease during follow-up. ${ }^{27}$ Thomas et al followed up 5873 patients with MI who underwent PCI for 3 years and found that the outcome of patients $\leq 40$ years is significantly better when compared with older patients. ${ }^{26}$ However, Yang et al demonstrated that very young MI patients ( $\leq 40$ years) had similar one-year and longer periods results when compared to those aged 41 to 50 despite having a lower prevalence of risk factors. ${ }^{5}$ A study that included 26,545 ACS patients from 2006 to 2017 revealed that subjects younger than 35 years were at significantly great risk of 30-day mortality. ${ }^{29}$ In our analysis, the CV and all-cause death in AMI individuals $<50$ years is significantly lower than that of patients $\geq 65$ years after adjustment for confounding factors. For death, the gap between adults aged $<50$ years and 50-65 years narrowed. One benefit of our study was the capability to present further assessment of non-CV death reasons. Respiratory failure and other reasons, except for cancer, sepsis, renal failure, gastrointestinal bleeding, and cerebrovascular disease were the main causes of death in young men. Patients with AMI may suffer from hemodynamic instability and fluid retention then resulting in gas exchange impairment and breathing difficulties. ${ }^{32}$ In our analysis, there were fewer patients $<50$ years present with the pulmonary disease when compared with those aged 50-65 years and those $\geq 65$ years. And we also found that the number of using ventilators was significantly higher in patients older than 65 years compared with those aged younger than 50 years. Despite a high survival rate, $12.5 \%$ of young men experienced one of the adverse events (nonfatal stroke, reoccurrence of MI, revascularization, or cardiac rehospitalization) during follow-up. The role of beta-blockers has been proved beneficial to prognosis. This study highlights the significance of secondary 
medication for coronary artery disease and the removal of modifiable risk factors in this group of patients.

One of the most common typical symptoms of AMI is acute precordial discomfort. Both atherosclerotic and non-atherosclerotic factors contributed to the development of AMI. Excessive alcohol assumption is related to chest pain, which may result in coronary occlusion due to endothelial disorder. ${ }^{33}$ Besides, a growing number of young people are in the rapid pace of modern life living with depression and anxiety, especially in big cities. Compared with older individuals, frequent exposure to high stress was a positive correlation with the risk of myocardial infarction in younger adults. ${ }^{34}$ In addition, systemic inflammatory reaction, hypercoagulation, and endothelial disorder may also cause MI. ${ }^{18}$ The risk of mortality in young men is lower while they were more likely to have higher levels of cardiac biomarkers in our study. Early identification and appropriate treatment for AMI remain significant in young individuals. Underlying mechanisms are essential to be analyzed intensively in this population.

\section{Limitations}

Study limitations should be noted in this work. First, it is a retrospective single-center analysis within the prospectively designed which is hard to demonstrate causal associations between clinical characteristics and outcomes. Second, patients who were too ill to be hospitalized were not enrolled in this study. Those people may have different characteristics compared with the remaining patients. Third, we were unable to evaluate stress, substance abuse, or physical activity which were recognized as risk factors prevalent among young patients presenting with AMI. Fourth, the study did not continue to gather longterm follow-up data about prescribed medical therapies and risk factor modification.

\section{Conclusions}

Age differences exist in long-term prognosis, especially $\mathrm{CV}$ and all-cause death after myocardial infarction. Although men who suffered from first AMI under the age of 50 had lower mortality, they had a higher prevalence of modifiable risk factors and were less probably to be prescribed post-AMI medical drugs except for betablockers. The findings emphasize that efficient advice such as physical activity and smoking cessation should be given from public health professions and governments to all young AMI patients.

\section{Ethics Approval and Consent to Participate}

The study protocol was approved by the study institutional review board of the Beijing Friendship Hospital affiliated to Capital Medical University (No:2021-P2-307-01). All relevant guidelines were followed for the study. The requirement for informed consent from patients was waived because of its retrospective design. All methods were carried out in accordance with the ethical standards of the institutional and the Declaration of Helsinki. The patient data is confidential. Any unauthorized use or disclosure of its contents is prohibited.

\section{Acknowledgments}

The authors gratefully acknowledge the assistance with data acquisition by Dr. Guoliang Zhao.

\section{Author Contributions}

All authors made a significant contribution to the work reported, whether that is in the conception, study design, execution, acquisition of data, analysis and interpretation, or in all these areas; took part in drafting, revising or critically reviewing the article; gave final approval of the version to be published; have agreed on the journal to which the article has been submitted; and agree to be accountable for all aspects of the work.

\section{Funding}

This research was supported by a grant from Beijing Key Clinical Subject Program.

\section{Disclosure}

All authors declare that they have no competing interests.

\section{References}

1. Karim MA, Majumder AA, Islam KQ, et al. Risk factors and in-hospital outcome of acute ST segment elevation myocardial infarction in young Bangladeshi adults. BMC Cardiovasc Disord. 2015;15:73. doi:10.1186/s12872-015-0069-2

2. Gupta A, Wang Y, Spertus JA, et al. Trends in acute myocardial infarction in young patients and differences by sex and race, 2001 to 2010. J Am Coll Cardiol. 2014;64(4):337-345. doi:10.1016/j. jacc.2014.04.054

3. Divakaran S, Singh A, Biery D, et al. Diabetes is associated with worse long-term outcomes in young adults after myocardial infarction: the partners YOUNG-MI registry. Diabetes Care. 2020;43 (8):1843-1850. doi:10.2337/dc19-0998

4. Yandrapalli S, Nabors C, Goyal A, Aronow WS, Frishman WH. Modifiable risk factors in young adults with first myocardial infarction. J Am Coll Cardiol. 2019;73(5):573-584. doi:10.1016/j. jacc.2018.10.084 
5. Yang J, Biery DW, Singh A, et al. Risk factors and outcomes of very young adults who experience myocardial infarction: the partners YOUNG-MI registry. Am J Med. 2020;133(5):605-612.e601. doi:10.1016/j.amjmed.2019.10.020

6. Murthy NS, Nandakumar BS, Pruthvish S, George PS, Mathew A. Disability adjusted life years for cancer patients in India. Asian Pac J Cancer Prev. 2010;11(3):633-640.

7. Gulati R, Behfar A, Narula J, et al. Acute myocardial infarction in young individuals. Mayo Clin Proc. 2020;95(1):136-156. doi:10.1016/j.mayocp.2019.05.001

8. Thygesen K, Alpert JS, Jaffe AS, et al. Fourth universal definition of myocardial infarction (2018). J Am Coll Cardiol. 2018;72 (18):2231-2264. doi:10.1016/j.jacc.2018.08.1038

9. Kannel WB, Abbott RD. Incidence and prognosis of unrecognized myocardial infarction. An update on the Framingham study. $N$ Engl JMed. 1984;311(18):1144-1147. doi:10.1056/NEJM198411013111802

10. Shah N, Kelly AM, Cox N, Wong C, Soon K. Myocardial infarction in the "young": risk factors, presentation, management and prognosis. Heart Lung Circ. 2016;25(10):955-960. doi:10.1016/j.hlc.2016.04.015

11. Cole JH, Miller JI 3rd, Sperling LS, Weintraub WS. Long-term follow-up of coronary artery disease presenting in young adults. $\mathrm{J} \mathrm{Am}$ Coll Cardiol. 2003;41(4):521-528. doi:10.1016/S0735-1097(02)02862-0

12. Lawesson SS, Stenestrand U, Lagerqvist B, Wallentin L, Swahn E. Gender perspective on risk factors, coronary lesions and long-term outcome in young patients with ST-elevation myocardial infarction. Heart. 2010;96(6):453-459. doi:10.1136/hrt.2009.175463

13. Jortveit J, Govatsmark RE, Langørgen J, et al. Gender differences in the assessment and treatment of myocardial infarction. Tidsskr nor Laegeforen. 2016;136(14-15):1215-1222. doi:10.4045/tidsskr.16.0224

14. Cui Y, Hao K, Takahashi J, et al. Age-specific trends in the incidence and in-hospital mortality of acute myocardial infarction over 30 years in Japan - report from the Miyagi AMI Registry Study. Circ J. 2017;81(4):520-528. doi:10.1253/circj.CJ-16-0799

15. Egred M, Viswanathan G, Davis GK. Myocardial infarction in young adults. Postgrad Med J. 2005;81(962):741-745. doi:10.1136/ pgmj.2004.027532

16. Naghavi M, Libby P, Falk E, et al. From vulnerable plaque to vulnerable patient: a call for new definitions and risk assessment strategies: part I. Circulation. 2003;108(14):1664-1672. doi:10.1161/01.CIR.0000087480.94275.97

17. Bentzon JF, Otsuka F, Virmani R, Falk E. Mechanisms of plaque formation and rupture. Circ Res. 2014;114(12):1852-1866. doi:10.1161/CIRCRESAHA.114.302721

18. van der Schoot GGF, Anthonio RL, Jessurun GAJ. Acute myocardial infarction in adolescents: reappraisal of underlying mechanisms. Neth Heart J. 2020;28(6):301-308. doi:10.1007/s12471-020-01408-y

19. Wu W, Berman A, Biery D, Blankstein R. Recent trends in acute myocardial infarction among the young. Curr Opin Cardiol. 2020;35 (5):524-530. doi:10.1097/HCO.0000000000000781

20. Gupta M, Gupta P, Mp G, Roy A, Qamar A. Risk factors for myocardial infarction in very young South Asians. Curr Opin Endocrinol Diabetes Obes. 2020;27(2):87-94. doi:10.1097/ MED.0000000000000532

21. Jalowiec DA, Hill JA. Myocardial infarction in the young and in women. Cardiovasc Clin. 1989;20(1):197-206.
22. Chen Y, Copeland WK, Vedanthan R, et al. Association between body mass index and cardiovascular disease mortality in east Asians and south Asians: pooled analysis of prospective data from the Asia Cohort Consortium. BMJ. 2013;347:f5446. doi:10.1136/bmj. f5446

23. Misra A, Wasir JS, Vikram NK, Pandey RM, Kumar P. Cutoffs of abdominal adipose tissue compartments as measured by magnetic resonance imaging for detection of cardiovascular risk factors in apparently healthy adult Asian Indians in North India. Metab Syndr Relat Disord. 2010;8(3):243-247. doi:10.1089/met.2009.0046

24. Misra A, Soares MJ, Mohan V, et al. Body fat, metabolic syndrome and hyperglycemia in South Asians. J Diabetes Complications. 2018;32(11):1068-1075. doi:10.1016/j.jdiacomp.2018.08.001

25. Shih CY, Chu ML, Hsieh TC, Chen HL, Lee CW. Acute myocardial infarction among young adult men in a region with warm climate: clinical characteristics and seasonal distribution. Int J Environ Res Public Health. 2020;17(17):6140. doi:10.3390/ijerph17176140

26. Wittlinger T, Seifert C, Simonis G, Gerlach M, Strasser RH. Prognosis in myocardial infarction of young patients: results of a prospective registry. Int J Cardiol. 2020;300:1-6. doi:10.1016/j. ijcard.2019.10.037

27. Jortveit J, Pripp AH, Langørgen J, Halvorsen S. Incidence, risk factors and outcome of young patients with myocardial infarction. Heart. 2020;106(18):1420-1426. doi:10.1136/heartjnl-2019-316067

28. Tung BW, Ng ZY, Kristanto W, et al. Characteristics and outcomes of young patients with ST segment elevation myocardial infarction undergoing primary percutaneous coronary intervention: retrospective analysis in a multiethnic Asian population. Open Heart. 2021;8 (1):e001437. doi:10.1136/openhrt-2020-001437

29. Qureshi W, Kakouros N, Fahed J, Rade J. Comparison of prevalence, presentation, and prognosis of acute coronary syndromes in $\leq 35$ years, 36-54 years, and $\geq 55$ years patients. Am J Cardiol. 2021;140:1-6.

30. Khoury S, Soleman M, Margolis G, et al. Incidence, characteristics and outcomes in very young patients with ST segment elevation myocardial infarction. Coron Artery Dis. 2020;31(2):103-108. doi:10.1097/MCA.0000000000000779

31. Yılmaz S, Coşansu K. Prognostic factors and outcomes in young patients with presented of different types acute coronary syndrome. Angiology. 2020;71(10):894-902. doi:10.1177/0003319720939444

32. van Diepen S, Katz J, Albert N, et al. Contemporary management of cardiogenic shock: a scientific statement from the American heart association. Circulation. 2017;136(16):e232-e268. doi:10.1161/ CIR.0000000000000525

33. Mostofsky E, van der Bom JG, Mukamal KJ, et al. Risk of myocardial infarction immediately after alcohol consumption. Epidemiology. 2015;26(2):143-150. doi:10.1097/EDE.0000000000000227

34. Lavie CJ, Menezes AR, De Schutter A, Milani RV, Blumenthal JA. Impact of cardiac rehabilitation and exercise training on psychological risk factors and subsequent prognosis in patients with cardiovascular disease. Can J Cardiol. 2016;32(10 Suppl 2):S365-s373. doi:10.1016/j.cjca.2016.07.508

International Journal of General Medicine

Dovepress

\section{Publish your work in this journal}

The International Journal of General Medicine is an international, peer-reviewed open-access journal that focuses on general and internal medicine, pathogenesis, epidemiology, diagnosis, monitoring and treatment protocols. The journal is characterized by the rapid reporting of reviews, original research and clinical studies

across all disease areas. The manuscript management system is completely online and includes a very quick and fair peer-review system, which is all easy to use. Visit http://www.dovepress.com/ testimonials.php to read real quotes from published authors. 